\title{
Addressing Policy Coherence Between Health in All Policies Approach and the Sustainable Development Goals Implementation: Insights From Kenya
}

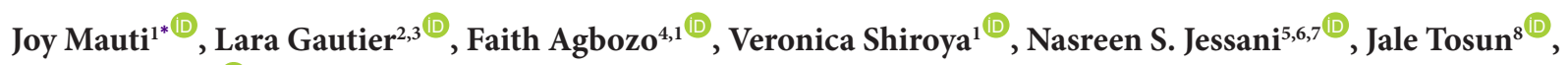 \\ Albrecht Jahn ${ }^{1}$ (D)
}

\begin{abstract}
Background: Addressing health in the Sustainable Development Goals (SDGs) calls for intersectoral strategies that mutually enhance both health promotion and sustainable development. Health in All Policies (HiAP) approach aims to address this as well as promote ownership among key stakeholders. Kenya was at the forefront of adopting the SDGs and has committed to the HiAP approach in its Health Policy document for the period 2014-2030. This study aims to assess how the adoption of the HiAP approach can leverage on SDGs implementation in Kenya.

Methods: This is an exploratory case study using qualitative data and some descriptive quantitative data. The Organisation for Economic Co-operation and Development's (OECD's) eight building blocks for policy coherence on sustainable development was our guiding framework. Qualitative data was derived from a review of relevant peer-reviewed and grey literature, as well as 40 key informant interviews and analyzed in NVIVO. Quantitative data was accessed from the United Nations SDG indicator database and exported to Excel.

Results: Kenya has expressed a strong political commitment to achieving the SDGs and has now adopted HiAP. The study showed that Kenya can leverage on local level implementation and long-term planning horizons that it currently has in place to address the SDGs as it rolls out the HiAP approach. The SDGs could be mapped out against the sectors outlined in the Adelaide statement on HiAP. It is also possible to map out how various ministries could coordinate to effectively address HiAP and SDGs concurrently. Funding for HiAP was not addressed in the OECD framework. Conclusion: Kenya can advance a HiAP approach by leveraging the ongoing SDGs implementation. This will be made possible by facilitating coordinated intersectoral action both at national and local level. Funding for HiAP is crucial for its propagation, especially in low- and middle-income countries (LMICs) and can be considered in the budgetary allocations for SDGs.

Keywords: Health Policy, Intersectoral Collaboration, Sustainable Development Goals, LMICs, Sub-Saharan Africa, Kenya

Copyright: (c) 2022 The Author(s); Published by Kerman University of Medical Sciences. This is an open-access article distributed under the terms of the Creative Commons Attribution License (https://creativecommons.org/licenses/ by/4.0), which permits unrestricted use, distribution, and reproduction in any medium, provided the original work is properly cited.

Citation: Mauti J, Gautier L, Agbozo F, et al. Addressing policy coherence between Health in All Policies approach and the Sustainable Development Goals implementation: insights from Kenya. Int J Health Policy Manag. 2022;11(6):757767. doi:10.34172/ijhpm.2020.212
\end{abstract}

Article History:

Received: 15 December 2019

Accepted: 14 October 2020

ePublished: 16 November 2020

\section{*Correspondence to:}

Joy Mauti

Email:

joy.mauti@uni-heidelberg.de

\section{Key Messages}

Implications for policy makers

- Policy-makers can utilize the proposed mapping of Sustainable Development Goals (SDGs) against the sectors outlined on the Adelaide statement on Health in All Policies (HiAP) to facilitate the HiAP approach adoption through SDG implementation.

- $\quad$ Policy-makers can promote creation or utilization of existing intersectoral groups and governance structures at local level for both HiAP and SDGs.

- $\quad$ Policy-makers, especially from low- and middle-income countries (LMICs), can use the Organisation for Economic Co-operation and Development's (OECD's) framework to assess policy coherence between health promotion strategies and sustainable development.

Implications for the public

This research shows how we can harmonize global policies with local realities -especially in a resource-limited setting. It shows the vital role local level structures and advocacy to promote policy adoption and implementation. This is particularly important in the case of Health in All Policies (HiAP) and Sustainable Development Goals (SDGs) implementation, as elaborated in this study. 


\section{Background}

The Linkage Between the Sustainable Development Goals and the Health in All Policies Approach

In September 2015, the United Nations member states adopted Agenda 2030 within which the 17 Sustainable Development Goals (SDGs) are supposed to be "integrated and indivisible," therefore complementary in nature. ${ }^{1}$ This calls for a systematic approach when evaluating the SDGs' synergies and tradeoffs. ${ }^{2}$ While SDG 3 aims to "ensure healthy lives and promote wellbeing for all at all ages," core health targets are either embedded in other goals or influenced by them..$^{2-5}$ Addressing these goals in order to promote health will require new ways of working, and ensuring stakeholder engagement. ${ }^{4-6}$

There are several encouraging strategies that have been considered in order to seek to advance health from an intersectoral perspective. For instance, the 2016 Shanghai declaration on health promotion intends to foster the interconnectedness of health and all SDGs. ${ }^{7}$ It also calls for political will to strengthen policy coherence for improved health equity and economic development. ${ }^{4}$ Health in All Policies (HiAP) is one such approach.

HiAP is defined as, "an approach to public policies across sectors that systematically takes into account the health implications of decisions, seeks synergies, and avoids harmful health impacts in order to improve population health and health equity." "As such, HiAP is a whole-of-government approach promoting all sectors to have a consideration for health. ${ }^{8}$ The HiAP approach also emphasizes the need for collaborative leadership within and between governments. ${ }^{8,9}$

In 2017, $150 \mathrm{HiAP}$ experts and practitioners representing 21 countries congregated in Adelaide, Australia and committed to fulfil the Shanghai Declaration ${ }^{10}$. In addition, in its ${ }^{13 \text { th }}$ General Programme of Work, 2019-2023, the World Health Organization (WHO) stated that, "Multisectoral action becomes possible when health actors are empowered to effectively engage in and support policy processes in other sectors. WHO will promote 'Health in All Policies' and governmental cabinet approaches to cross-sectoral action and policy coherence."11 The 2019 World Health Assembly resolution A72/11 also reiterates the importance of a coordinated intersectoral action and especially HiAP in implementing the SDGs. ${ }^{6}$

Given clear resonance between the SDG intentions and the HiAP approach, the SDGs provide a unique opportunity to advance HiAP. ${ }^{12,13}$ Ramirez-rubio et al in 2018 outlined some of the opportunities SDGs present in addressing some challenges that affect HiAP as shown in Table 1.

Health in All Policies and Sustainable Development Goals in Kenya

Literature on health-related intersectoral action and SDGs is sparse in low- and middle-income Countries (LMICs). ${ }^{26-28}$ However, several studies do cover African policy-makers' views on how to achieve the SDGs. ${ }^{29-31}$ Kickbusch et al in 2017 highlighted South Sudan, Namibia and Zambia as examples of African countries that have adopted a HiAP approach although still in early stages - to advance the SDGs. ${ }^{4}$

Kenya is committed to the HiAP approach as per its sixth policy objective in the Kenya health policy document for 2014-2030 which aims to "strengthen collaboration with private and other sectors that have an impact on health" and explicitly addresses various social determinants of health through HiAP. ${ }^{32}$

"The policy will also seek to influence the following social determinants of health: women's literacy, access to safe water and adequate sanitation, nutrition, safe housing, occupational hazards, road safety, security, income, and community participation, among others." ${ }^{32}$

Scholars note that the adoption of the HiAP approach in Kenya can be an important "win-win" approach for Kenya by maximizing on its policy coherence with the SDGs. ${ }^{33,34}$ This empirical study thus contributes to the literature by specifically addressing how HiAP adoption can leverage implementation of the SDGs in Kenya.

Study Aims

The study had several aims:

1. Understand how a HiAP approach can leverage development agendas promoting the SDGs.

2. Assess how both the HiAP approach and the SDGs' implementation were articulated in Kenyan policy documents, and how they are perceived by the various stakeholders.

3. Offer insights into the opportunity of developing a monitoring and reporting framework for Kenya's HiAP approach using SDG indicators.

Conceptual Framework: OECD’s Policy Coherence for Sustainable Development

To assess the congruence between HiAP and SDGs in Kenya, we perused the Organisation for Economic Co-operation and

Table 1. Examples of HiAP Challenges Addressed Within the SDGs

\begin{tabular}{|c|c|}
\hline HiAP Challenges & Opportunities Through the Implementation of SDGs \\
\hline Disparities between political and technical health aspects. ${ }^{14-16}$ & $\begin{array}{l}\text { The SDGs encourages holistic thinking in governance to address both } \\
\text { technical and political processes. }{ }^{17}\end{array}$ \\
\hline Lack of HiAP awareness outside the health sector. ${ }^{18-20}$ & The SDGs are universally accepted; therefore, can raise awareness for \\
\hline HiAP falling off the political agenda over time. ${ }^{17}$ & HiAP. $^{19}$ \\
\hline Limited research on funding and governance mechanisms for HiAP. ${ }^{17,21}$ & $\begin{array}{l}\text { "Avalanche" of research addressing funding and governance } \\
\text { mechanisms for SDGs. }{ }^{22}\end{array}$ \\
\hline
\end{tabular}

Abbreviations: SDGs, Sustainable Development Goals; HiAP, Health in All Policies. Source: Ramirez-Rubio et al. ${ }^{25}$ 
Development's (OECD's) Policy Coherence for Sustainable Development (PCSD) framework, which was developed in 2016. ${ }^{35}$ According to the PCSD Framework, policy coherence is defined as, "the process of fostering synergies across economic, social and environmental policy areas; identifying trade-offs and reconcile domestic and international objectives; and addressing the spill-overs of domestic policies on other countries and on future generations." ${ }^{35}$ Figure shows the PCSD framework 8 building blocks which are in line with the SDG Target 17.14 that addresses PCSD. ${ }^{35}$ This framework helps us to explore the economic, political and social areas that are important for both HiAP and SDGs. The PCSD building blocks also address very similar thematic areas that Ramirez-Rubio et al proposed as areas of linkages between HiAP and SDGs.

The framework above highlights critical aspects with respect to (a) political commitment, $(b)$ the importance of inclusion (stakeholder engagement, subnational and local involvement), (c) Policy coherence (coordination, integration and effects), (d) long term planning, and (e) Monitoring and reporting. Throughout these building blocks there is an emphasis on intersectoral collaboration (ISC), multistakeholder engagement, and accountability which provides a formidable foundation for assessing the congruence of HiAP approach with the SDGs as seen in Table 2.

\section{Methods}

Study Design

This is an exploratory case study using qualitative data and some descriptive quantitative data. ${ }^{36,37}$ The case being studied is the HiAP approach adoption in Kenya, a LMIC, in the context of SDGs implementation. According to Stake's typology, a case study is important because it enables us to delve into the "particularity and complexity of a single case," thus enabling us to better consider the peculiarities of the case. ${ }^{36,37}$ Data

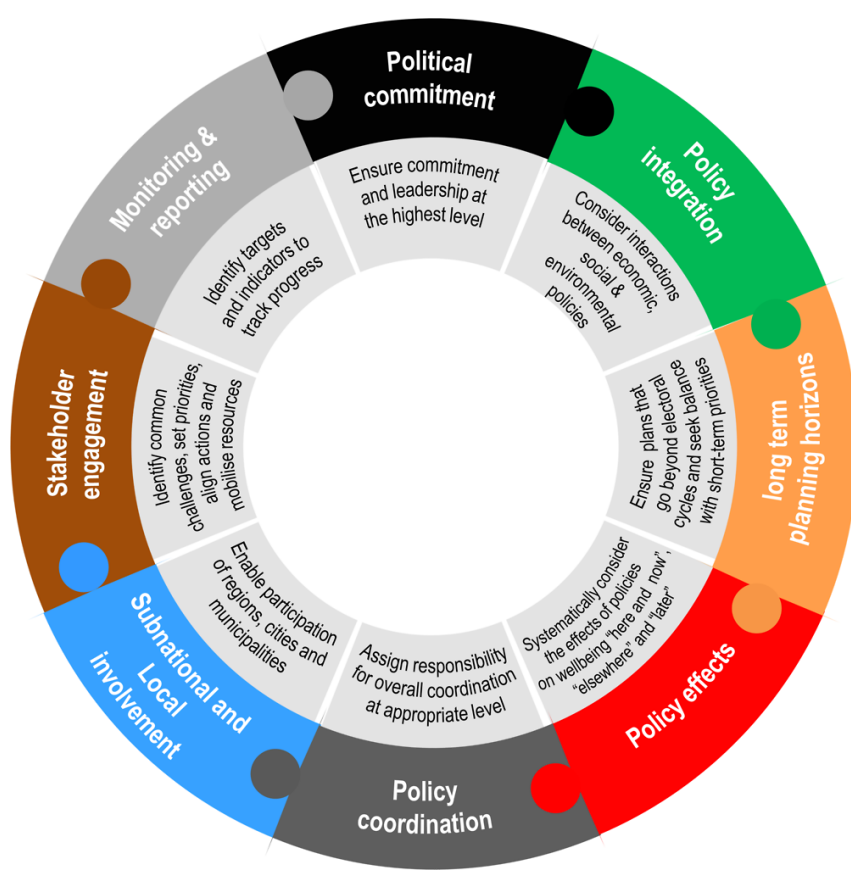

Figure. PCSD Building Blocks. Abbreviation: PCSD, policy coherence for sustainable development. Source: OECD. ${ }^{35}$ sources for qualitative analysis included peer-reviewed and grey literature as well as key informant interviews. The United Nations SDG indicator database for Kenya was used to access the quantitative data reported in this study.

\section{Study Setting}

Kenya is categorized as a lower middle-income economy with $36.1 \%$ of the population living in extreme poverty (surviving on less than $\$ 1.90$ a day) in 2015/2016. ${ }^{38}$ The Kenyan population also suffers an uneven access to healthcare. ${ }^{39}$ In an attempt to address a highly centralised and hierarchical government which was affected by corruption, the government effectively engaged in a process of decentralization following the promulgation of the 2010 Constitution of Kenya. ${ }^{40,41}$ Devolution - one form of decentralization - resulted in one National Government and 47 decentralized governments. ${ }^{42,43}$

According to the constitution, the two levels of governments are interdependent and undertake their relations through consultation and cooperation. ${ }^{44}$ This cooperation is supposed to promote formulation and implementation of socioeconomic policies. ${ }^{40,45}$ The central government retains policy development and management of overall national and international affairs. ${ }^{45,46}$ The county governments oversee policy implementation within their designated geographical location. ${ }^{47}$ For SDG implementation, counties develop their own county integrated development plans (CIDPs) which must align with Vision 2030 Medium-Term Plans (MTPs) in that given period. ${ }^{41}$ Table 3 summarizes Kenya's lead institutions as well as key policy documents for SDGs.

\section{Data Collection}

\section{Literature Review}

Peer-reviewed literature was retrieved from PubMed database using a combination of keywords related to HiAP and SDGs. Google Scholar and Google were perused for both peerreviewed as well as grey literature searches as seen in Table 4 .

\section{Interviews}

Interviewees selection: Purposeful and snowball sampling approaches were used to select key informants. The first author, who is Kenyan, approached all Kenya's government

Table 2. Operationalization of the OECD Building Blocks for Policy Coherence Between HiAP and SDGs

\begin{tabular}{|c|c|}
\hline Aim & Building Blocks \\
\hline $\begin{array}{l}\text { How HiAP can leverage on the } \\
\text { development agendas that } \\
\text { address SDGs }\end{array}$ & $\begin{array}{l}\text { 1. Political commitment } \\
\text { 2. Long-term planning horizons } \\
\text { 3. Subnational and local } \\
\text { involvement }\end{array}$ \\
\hline $\begin{array}{l}\text { How HiAP adoption and } \\
\text { implementation can progress } \\
\text { alongside SDGs implementation }\end{array}$ & $\begin{array}{l}\text { 1. Policy Integration } \\
\text { 2. Policy coordination } \\
\text { 3. Institutional coordination } \\
\text { 4. Stakeholder engagement }\end{array}$ \\
\hline $\begin{array}{l}\text { Assess whether or not a } \\
\text { monitoring and reporting } \\
\text { Framework for HiAP can be } \\
\text { developed using SDG indicators }\end{array}$ & $\begin{array}{l}\text { 1. Monitoring and reporting } \\
\text { 2. Policy effects }\end{array}$ \\
\hline
\end{tabular}

Abbreviations: SDGs, Sustainable Development Goals; HiAP, Health in All Policies; OECD, Organisation for Economic Co-operation and Development. 
Table 3. Kenya's Key SDG Institutions, Actors and Policy Documents

\begin{tabular}{|c|c|c|c|}
\hline Administrative Level & Lead Institutions & Policy Documents & Legality \\
\hline National & $\begin{array}{l}\text { Ministry of Devolution and Planning - SDGs } \\
\text { coordinating department }\end{array}$ & $\begin{array}{l}\text { - } \quad \text { Vision } 2030(2007) \\
\text { - } \quad \text { MTP } 32018-2022(2018)\end{array}$ & $\begin{array}{ll}- & \text { Binding } \\
\text { - } & \text { Binding }\end{array}$ \\
\hline County & $\begin{array}{l}\text { - } \quad \text { Office of Director of planning and economic affairs } \\
\text { - } \quad \text { Council of Governors }\end{array}$ & $\begin{array}{l}\text { - CIDPs (various dates) } \\
\text { - County of governors committee work } \\
\text { plans (various dates) }\end{array}$ & $\begin{array}{ll}- & \text { Binding } \\
\text { - } & \text { Binding }\end{array}$ \\
\hline
\end{tabular}

Abbreviations: SDGs, Sustainable Development Goals; CIDPs, county integrated development plans; MTPs, medium-term plans.

Table 4. Overview of the Literature Review and Selection Process

\begin{tabular}{|c|c|c|}
\hline Selection Process & Peer-Reviewed Literature & Grey Literature \\
\hline Language & English & English \\
\hline Search Terms & $\begin{array}{l}\text { PubMed: "Health in All Policies," "Health in All Policies" AND } \\
\text { Development, "Health in All Policies" AND SDGs, "Health } \\
\text { in All Policies" AND policy coherence, SDGs AND policy } \\
\text { coherence. }\end{array}$ & $\begin{array}{l}\text { Google Scholar: HiAP and SDGs, Policy coherence and SDGs, } \\
\text { Trade-offs between SDGs, Synergies between SDGs, HiAP and } \\
\text { policy coherence. } \\
\text { Google: Kenya and SDGs, Kenya and HiAP, Kenya Vision 2030, } \\
\text { Kenya CIDPs, Kenya and Intersectoral governance. }\end{array}$ \\
\hline Publication type & Original research, all kinds of reviews and commentaries. & $\begin{array}{l}\text { Websites, reports, and any content related to HiAP and } \\
\text { SDGs in Kenya. }\end{array}$ \\
\hline Documents selected & $\begin{array}{l}\text { Out of the total } 400 \text { results } 50 \text { were selected. } 54 \text { other } \\
\text { relevant papers were identified }(N=104) .\end{array}$ & $\begin{array}{l}\text { National policy documents }=57 . \text { National documents } \\
\text { obtained from interviewees }=3 . \text { International documents }= \\
31(\mathrm{~N}=91) .\end{array}$ \\
\hline Grand total & 195 documents & \\
\hline
\end{tabular}

Abbreviations: SDGs, Sustainable Development Goals; HiAP, Health in All Policies; CIDPs, county integrated development plans.

ministries - either by email, telephone, or physically at ministry offices - from August 2016 to March 2017 to recruit interviewees. Formal requests were addressed to the office of the permanent secretary in every ministry. From there, the interviewer was directed to the designated interviewee. The interviewees were either working at the highest level of policy-making or working at technical level in the ministry.

Participant overview: 16 out of the total 20 ministries in Kenya in 2016/2017 were contacted and agreed to have representatives interviewed. Representatives from the government were all from the national level and ranged in positions from Under-Secretaries to Economists, Policy Directors, Head of Departments and Department members. In addition, a list of potential key informants from outside the ministries was generated and snowball sampling was used to contact representatives from development partners, civil society, academia and policy institutes. In total 24 government officials, 6 development partners, 2 Heads of NGO Consortiums, 1 NGO, 3 academic professors, 2 policy analysts and 2 independent consultants were interviewed. Most of the interviewees outside the health sector were not aware of HiAP approach but were very familiar with the concept of ISC and that is what was leveraged on.

Instrument development and use: Interview guides used to obtain data from key informants in government and nongovernment sectors were developed and tested. The questions explored interviewees' knowledge of HiAP or ISC; their knowledge and perception of Kenya's involvement in MDGs and SDGs, thoughts on the role of HiAP/ISC in relation to the SDGs for HiAP, and economic consideration for HiAP/ ISC - whether it was profitable or not to adopt this approach and Vision 2030. Although the OECD analytical framework was adopted after the interviews had been done, there were some similarities between the questions asked and the OECD building blocks, especially political commitment, policy integration, policy and institutional coordination and stakeholder engagement. Interviews were conducted in English with extensive notes taken. All but 4 provided consent to be audio recorded Extensive notes were taken in all interviews.

\section{United Nation Sustainable Development Goal Indicators Database}

To assess whether a monitoring and reporting framework could be developed, all the relevant SDGs were mapped out against the social determinants Kenya highlighted under the HiAP policy objective. We then assessed the United Nations global SDG indicator database to retrieve data for Kenya by first selecting the indicator under the given target and goal, then the geographical location, the years from 2015 onwards and finally by downloading the data as an excel sheet. ${ }^{48}$

\section{Data Analysis}

All the documents retrieved were uploaded in an Endnote file. They were then screened for content specifically related to our thematic area, and extracted relevant data onto Word documents which were uploaded to NVIVO 12 for further analysis. We then discussed the results obtained for Kenya with regards to the peer-reviewed literature. Budget analysis was done by reviewing all the 47 CIDPs budgets in detail to see how the counties allocated funds for their stated projects, and whether or not the allocation was per the SDGs. The main 
policy documents pertaining to health and SDGs reviewed in Kenya are listed in Table 5.

All interviews were transcribed and uploaded into NVIVO 12 , and then analyzed using a qualitative framework analysis which is a procedure to assess qualitative data by sorting and charting it in accordance with key issues and themes in the given research study. ${ }^{60,61}$ A deductive approach was used, whereby the OECD framework on policy coherence's 8 building blocks guided the coding and analysis. The blocks served as the major themes of the codebook. Starting from these themes, we coded the material ie, interview transcripts, literature in NVIVO using an iterative approach whereby subthemes and codes were identified and refined as we progressed through the analysis.

\section{Results}

The results report interviewees' perspectives on HiAP and SDGs implementation as well as data from literature and the SDGs database. The results have been presented in accordance to the 8 PCSD building blocks under the 3 objectives of the study.

\section{Understand How a HiAP Approach Can Leverage Development} Agendas

\section{OECD Building Block: Political Commitment}

Political commitment and leadership at the highest level of government is essential for both HiAP and SDGs. Kenya's strong commitment to both the SDGs and Africa Union's Agenda 2063 has been facilitated by political leadership and an Inter-Agency Technical Working Group which was established in early 2015. ${ }^{52}$ This Working Group comprises representatives from all the ministries, Kenya's National Bureau of Statistics, National Council for Population and Development, civil society, and the private sector. ${ }^{49}$

Political commitment for HiAP in Kenya is evidenced by it being outlined as a policy objective in the Kenya Health Policy 2014-2030. As confirmed by one interviewee, the
HiAP approach was proposed by a former Minister of Health during her tenure as one of the commissioners of the global commission for social determinants of health.

As the Ministers of Health and other health professionals are part of the Inter-Agency technical working group, they have an opportunity to propagate for HiAP in these meetings as an approach that encourages holistic thinking in governance.

\section{OECD Building Block: Long-term Planning Horizons}

Vision 2030 has been divided into multiple 5-year MTPs. MPT3 (2018-2022) and MTP4 (2023-2028) are expected to mainstream the SDGs. ${ }^{49,52,62}$ In addition, Kenya has to honor regional commitments, in particular the African Union's Agenda 2063 which is this continent's blueprint for development for the period 2013 to $2063 .^{51,54,62}$ Through its long-term outlook, 17 interviewees indicated that Vision 2030 supersedes the political challenges of electoral cycles and personal whims of politicians and ensures that every new party maintains their obligation to it.

"What I would say is that Vision 2030 and SDGs are very good because they enable us implement what every government is planning and being a long-term kind of planning blueprint, it is able to avoid politics. So, any political party that will come to run the country finds Vision 2030 is there being implemented, finds the SDG targets are there they are set. What you add into it, they are just like flavour you come with in your manifesto" (KI39 - Government official).

Ten interviewees indicated that Vision 2030 tries to bring all development aspects that are linked to health.

"[Vision 2030] is the only thing that tries to bring together all the ingredients of health for all, but it is difficult to define how this happens in the Kenyan scene. You can only point to Vision 2030 and say - looking at the social pillar, the economic pillar, socio-economic pillars - That is where you can see some kind of concerted effort to look at the health in all policies" (KI13 - Independent Consultant).

Table 5. Reviewed National Policy Documents and Reports (Grey Literature)

\begin{tabular}{|c|c|c|c|}
\hline Title & Addressing SDGs or HiAP? & Publication Year & Reference \\
\hline Implementation of the Agenda 2030 for Sustainable Development in Kenya & SDGs & 2017 & 49 \\
\hline Guidelines for preparation of county Integrated development plans (revised) & SDGs & 2017 & 50 \\
\hline $\begin{array}{l}\text { Vision 2030's Medium Term Plan as a Framework for Implementation of the } \\
\text { Sustainable Development Goals }\end{array}$ & SDGs & 2016 & 51 \\
\hline Voluntary national review of progress on SDGs in Kenya & SDGs & 2017 & 52 \\
\hline Kenya Vision 2030: The Popular Version (2007) & SDGs/HiAP & 2007 & 54 \\
\hline Vision 2030 Third Medium Term Plan 2018-2022 & SDGs/HiAP & 2018 & 55 \\
\hline Kenya Health Policy 2014-2030 & HiAP & 2014 & 32 \\
\hline $\begin{array}{l}\text { Addressing the Social Determinants of Health in Kenya: Framework for Health in All } \\
\text { Policies and Inter-sectoral Action }\end{array}$ & HiAP & 2013 & 56 \\
\hline Reforming health care in Kenya: prospects for health-in-all policies approach & HiAP & 2011 & 57 \\
\hline Review of social determinants of health and health indicators in Kenya & HiAP & 2013 & 58 \\
\hline County Integrated Development Plans & SDGs/HiAP & 2020 & 59 \\
\hline
\end{tabular}

Abbreviations: SDGs, Sustainable Development Goals; HiAP, Health in All Policies. 
The current Health Policy document has the same timeline as the Vision 2030 which provides an opportunity for HiAP to be mainstreamed simultaneously with the SDGs.

\section{OECD Building Block: Subnational and Local Involvement}

An SDGs Liaison office within the secretariat of the Council of Governors for the counties has been created in order to facilitate coordination between the national and the county government. Specifically, for ISC, 14 interviewees indicated that the devolved system of government posed an opportunity for its implementation at the county level.

"I would say this: at the county level, these divisions we have at national level begin to fade out, because we sort [of] have like these divisions and division heads who it is really easy for them to sit [together]. The guy in the ministry of water or the ministry of education for them to sit on the same table with someone from the ministry of health is really easy because it a smaller area of operation" (KI40 - NGO representative).

Three interviewees talked about multi stakeholder health promotion structures called the Health Promotion Advisory Committee (HPAC). They also stated that it was important for the establishment of HPACs both at national and county level.

"There were a number of recommendations and one was to have a HPAC at the national level and at the county level because after devolution, we realize that there are some policies which would be made at the county level. So, it would not be enough to have a committee at the national level, we still need some platforms at the county level so that whatever policies or whatever communication are developed at national level they can have a platform at county level to be discussed before it goes to the community" (KI18 International NGO Representative).

HPACs consist of members from major economic sectors, religious leaders, and "village champions" who are tasked with advising the county on health issues. The HPACs are led by the County Health Promotion officer have several responsibilities: advocacy on resources and policy; lobbying for funds; and disseminating policy communications from the national level to the county level. HPAC members translate these policy communications, if possible, into the national language (Kiswahili) or into local languages. At the time of this study, there were 33 out of 48 possible HPACs (47 at the county level and one at the national level) in place.

HPACs offer an opportunity for the HiAP approach to be established at local level. The HPACs could collaborate with the SDGs Liaison office at the as they already have a diverse set of representatives who can leverage on health promotion to be a central focus in sustainable development.

\section{HiAP Adoption and SDGs Implementation in Kenya OECD Building Block: Policy Integration}

Policy integration ensures that there is a balance in addressing the economic, social and political dimensions of development. ${ }^{35}$ While Vision 2030 addresses all 3 dimensions, 4 interviewees indicated that some sectors received more attention than others.
"One of its weaknesses is that it [Vision 2030] is very ambitious. It requires a lot of revenue generation from the government and that didn't happen and so that means of course some sectors in my view are starved of the resources" (KI7 - Government Official).

Policy integration also aims to ensure that the global agenda is addressed at regional, national and local levels within a nation. ${ }^{35}$ The current MTP3 for the period 2018-2022 which informs the second generation of CIDPs explicitly shows how the SDGs will be implemented but only mentions that it is aligned with the 7 aspirations of the Agenda $2063 .{ }^{55}$ A study conducted by the SDGs Kenya forum found out that it was a challenge for some goals and targets to fit in properly within Vision 2030's MTPs which inform the CIDPs. ${ }^{51}$ These were the goals addressing multilateral partnerships, development assistance, immigration and regional integration, which will not be easy to address, especially at the county level..$^{51}$

All 47 CIDPs were reviewed with 44 county CIDPs mentioning links to Agenda 2030 and 30 county CIDPs mentioning links to Agenda 2063. Only 3 CIDPs directly addressed each SDG. Given that budgets are considered an essential tool for policy integration, all 47 CIDP budgets were reviewed. ${ }^{35}$ Only one county in one draft of their CIDP showed how they allocate funds per SDGs. ${ }^{63}$

Therefore, the sectors under HiAP could be integrated in the Vision 2030 as they both address the economic, political and economic aspects of development. This can also assist in equitable focus on the sectors especially in the budgetary allocations. Additionally, by collaborating with the SDG liaison office, the HPACs have better chances to lobby for budgetary allocations for health as opposed to competing for the funds.

OECD Building Blocks: Policy and Institutional Coordination and Stakeholder Engagement

In Kenya, the Ministry of Devolution and Planning coordinates SDG implementation across the ministries and at the county level. There is a specific SDGs office within the ministry that facilitates both government and nongovernment stakeholders' engagement. This SDGs office also works with the Inter-Agency Technical Working group. Outside the government, there is the SDG Kenya forum, which was initiated by the civil society in Kenya. The forum not only coordinates civil society engagement in the SDGs but acts as the liaison between the civil society and the government. All interviewees agreed that the implementation of the SDGs is a great opportunity to improve ISC at all government levels.

"The intersectoral collaboration is very key in terms of helping Kenya [to] achieve the SDGs. That synergy is very key because it is the coordination framework that will help to midwife [facilitate] those results and I think there is commitment from stakeholders especially in government to ensure that that collaboration continues and is strengthened" (KI32 - Development Partner).

Ministry of Health could leverage these established structures and collaborations at all government levels and beyond to not only create awareness but also establish HiAP. Table 6 illustrates an example of how ministries could 
collaborate or take up leadership roles in facilitating ISC to address both HiAP and SDGs in Kenya.

Assessing if HiAP Can Be Monitored and Reported Using SDGs in Kenya

OECD Building Block: Monitoring and Reporting HiAP Using SDGs Indicators

The OECD principle of monitoring and reporting proposes the need to identify and use targets and indicators to track progress. ${ }^{35}$ Table 6 maps out the SDGs in relation to the specific sectors stated in the Adelaide Statement on HiAP and the social determinants of health highlighted in the Kenya Health Policy document. We used the Environment and Sustainability sector as an example to illustrate how the progress to attain access to safe water and adequate sanitation can be monitored using the SDG indicators.

Safe water and adequate sanitation are essential to prevent outbreaks of water-borne diseases such as cholera which Kenya is prone to. SDGS $6,7,13,14$, and 17 are all relevant to this sector. Specifically, SDG 6 addresses availability and sustainable management of water and sanitation for all. Table 7 lists examples of relevant indicators under SDG 6.

The proportion of the Kenyan population using safely managed drinking water services in the urban area dropped from $51.7 \%$ in 2015 to $50.0 \%$ in 2017 . The proportion of the population practicing open defecation as a component of safely managed sanitation services declined from $11.1 \%$ in 2015 to $10.3 \%$ in 2017 in both rural and urban areas. The proportion of the population with basic hand washing facilities both in rural and urban areas remained constant between 2015 and 2017 at 24.6\%. In 2017, 35.5\% of the water bodies in Kenya had good ambient water quality. Water usage efficiency was recorded at $\$ 10.9$ per cubic meter in 2015. Still in 2015, there was only $33.2 \%$ of fresh-water resources available.

From the available data, Kenya is off-track ensuring access to safe water and adequate sanitation for all Kenyans by 2030 .

\section{OECD Building Block: Policy Effects}

Addressing a policy's impact and effect is a key building block in facilitating PCSD ${ }^{35}$. Countries all over the world are realizing the importance of impact assessments to ensure sustainability of development policies. ${ }^{35,64}$ More specifically, health impact assessment (HIA) is recognized as one potentially powerful tool that can be used to support HiAP. ${ }^{65}$ Implementation of SDGs has been seen as an opportunity for countries to introduce HIA. ${ }^{64}$

Interview statements were contradictory with some interviewees indicating that impact assessments are done occasionally, whereas others said they are always done. In terms of who conducts the assessments, we were met with an equal variety of responses including: private consultants, civil society organizations, National Environmental Management Agency (NEMA) etc. It is worth noting that NEMA is mandated to conduct Environmental Impact Assessments in Kenya, which some interviewees mentioned they use as a "proxy" for HIA. However, dissemination of NEMA recommendations is suboptimal as expressed by 3 interviewees.

"NEMA will send us a report of Environmental Impact
Assessments of a proposal with project of course it may be sent to health [Ministry of Health], [The reports] may be sent to Nairobi City County but again that synchronization is not there" (K5 - Government Official).

In summary, with availability of data, SDG goals and indicators could be used as a component of monitoring the progress of the sectors outlined in the Adelaide statement on HiAP. There is a need to recognize HIA as an essential tool to support HiAP.

\section{Discussion}

In the discussion, we reflect on the 3 aims we embarked on using the OECD's building blocks for effective policy coherence in Kenya, as it related to HiAP and SDGs.

Understand How a HiAP Approach Can Leverage Development Agendas Promoting the SDGs

Consistent with literature, we found that the HiAP approach faces challenges in moving from rhetoric to practice. ${ }^{66,67}$ Electoral cycles and political party preferences have often upended HiAP and SDG implementation thereby stressing the importance of instating more robust structures and processes for embedding HiAP into government policies. ${ }^{35}$ This can be done by explicitly including HiAP in the Vision 2030 similar to Namibia, Sudan, Zambia and Suriname who have used national development plans to successfully adopt HiAP $^{68}$ These countries did this as a way to give health a central focus on development as part of the whole-ofgovernment approach. ${ }^{68,69}$ By explicitly stating that HiAP will be the core approach for Vision 2030, there will be a mutual benefit of visibly tracking the progress of in-country policy interventions to regional and global benchmarks.

Assess How Both the HiAP Approach and the SDGs' Implementation Were:

a) Articulated in Kenyan Policy Documents

With respect to policy integration, the study found that Vision 2030 has aligned with Agenda 2030 and Agenda 2063, but not seamlessly. This was also the same finding by the SDG Kenya Forum's 2016 analysis of these two agendas in relation to Kenya's Vision $2030 .{ }^{51}$ In this report, the forum suggests that specific targets, as highlighted within the different agendas ought to be visibly outlined in implementation matrices, to allow for comparative monitoring of Kenya's incountry progress of interventions and assess its ambitions towards meeting continental and global targets. ${ }^{51}$ In spite of the highlighted gaps, the forum experts deemed the existing processes as sufficient to support the country's progress for achieving SDGs and Agenda 2063. ${ }^{11}$

b) How They Are Perceived by the Various Stakeholders Our study demonstrated that policy coordination and mapping of stakeholders' engagement is at the core of propagating HiAP and SDGs, and assist with strengthening existing mechanisms for both horizontal and vertical co-ordination. ${ }^{67,70}$ However, "turf wars" do exist and without appropriate co-ordination mechanisms to allow ministries, public sector agencies and other key stakeholders to share information, define and 
Table 6. Suggested Linkages Between Social Determinants of Health in the Current Kenya Health Policy 2014-2030 and the Relevant SDGs

\begin{tabular}{|c|c|c|c|c|}
\hline $\begin{array}{l}\text { Sectors According to } \\
\text { Adelaide Statement }\end{array}$ & $\begin{array}{l}\text { Kenya's Health Policy Social } \\
\text { Determinants of Health focus }\end{array}$ & SDGs & Example of Collaborating/Leading Ministries & $\begin{array}{l}\text { Examples of Cross Cutting } \\
\text { Ministries }\end{array}$ \\
\hline Education and early life & Women's literacy & $\begin{array}{l}\text { SDG 4: Ensure inclusive and equitable quality education and promote } \\
\text { lifelong learning opportunities for all }\end{array}$ & $\begin{array}{ll}\text { - } & \text { Ministry of Education } \\
\text { - } & \text { Ministry of Public Service, Youth \& Gender Affairs } \\
\text { Ministry of Sports, Culture and the Arts }\end{array}$ & \multirow{8}{*}{$\begin{array}{l}\text { - Ministry of Interior and } \\
\text { Coordination of National } \\
\text { Government } \\
\text { - Ministry of Defence } \\
\text { - Ministry of Devolution and } \\
\text { - Planning } \\
\text { - Ministry of Finance \& } \\
\text { National Treasury }\end{array}$} \\
\hline $\begin{array}{l}\text { Environment and } \\
\text { sustainability }\end{array}$ & Access to safe water & $\begin{array}{l}\text { SDG 6: Ensure availability and sustainable management of water and } \\
\text { sanitation for all } \\
\text { SDG 7: Ensure access to affordable, reliable, sustainable and modern energy } \\
\text { for all } \\
\text { SDG 13: Take urgent action to combat climate change and its impacts } \\
\text { SDG 14: Conserve and sustainably use the oceans, seas and marine } \\
\text { resources for sustainable development } \\
\text { SDG 15: Protect, restore and promote sustainable use of terrestrial } \\
\text { ecosystems, sustainably manage forests, combat desertification, and halt } \\
\text { and reverse land degradation and halt biodiversity loss }\end{array}$ & $\begin{array}{ll}- & \text { Ministry of Water \& Irrigation } \\
-\quad & \text { Ministry of Environment, and Natural Resource } \\
\text { - } & \text { Ministry of Mining }\end{array}$ & \\
\hline Agriculture and food & Adequate nutrition & $\begin{array}{l}\text { SDG 2: End hunger, achieve food security and improved nutrition and } \\
\text { promote sustainable agriculture } \\
\text { SDG 12: Ensure sustainable consumption and production patterns }\end{array}$ & - Ministry of Agriculture, Livestock and Fisheries & \\
\hline $\begin{array}{l}\text { Housing and community } \\
\text { services }\end{array}$ & Safe housing & $\begin{array}{l}\text { SDG 11: Make cities and human settlements inclusive, safe, resilient and } \\
\text { sustainable }\end{array}$ & - Ministry of Land, Housing and Urban Development & \\
\hline $\begin{array}{l}\text { Economy and } \\
\text { employment }\end{array}$ & $\begin{array}{l}\text { Occupational hazards, } \\
\text { unemployment }\end{array}$ & $\begin{array}{l}\text { SDG 8: Promote sustained, inclusive and sustainable economic growth, full } \\
\text { and productive employment and decent work for all }\end{array}$ & $\begin{array}{l}\text { - Ministry of Labour \& East Africa Affairs } \\
\text { - } \quad \text { Ministry of Industrialization and Enterprise } \\
\text { - } \quad \text { Mevelopment } \\
\text { - Ministry of Foreign Affairs \& International Trade } \\
\quad \text { Ministry of East Africa Affairs, Commerce, and Tourism }\end{array}$ & \\
\hline $\begin{array}{l}\text { Infrastructure and } \\
\text { planning and transport }\end{array}$ & Road safety & $\begin{array}{l}\text { SDG 9: Build resilient infrastructure, promote inclusive and sustainable } \\
\text { industrialization and foster innovation }\end{array}$ & $\begin{array}{l}\text { - } \quad \text { Ministry of Transport and Infrastructure } \\
\text { - } \quad \text { Ministry of Energy and Petroleum }\end{array}$ & \\
\hline Security and justice & Security & $\begin{array}{l}\text { SDG 16: Promote peaceful and inclusive societies for sustainable } \\
\text { development, provide access to justice for all and build effective, } \\
\text { accountable and inclusive institutions at all levels }\end{array}$ & - $\quad$ Ministry of Defence & \\
\hline Land and culture & - & - & $\begin{array}{l}\text { - } \quad \text { Ministry of Land, Housing and Urban Development } \\
\text { - } \quad \text { Ministry of Sports, Culture and the Arts }\end{array}$ & \\
\hline
\end{tabular}

Multisectoral

SDG 1: End poverty in all its forms everywhere

SDG 5: Achieve gender equality and empower women and girls

SDG10: Reduce inequality within and among countries

SDG 17: Revitalize the global partnership for sustainable development

Abbreviation: SDG, Sustainable Development Goal.

Notes: Sources include the Adelaide Statement on HiAP (column 1), Kenya Health Policy document 2014-2030 (column 2), SDGs document (column 3).

764 International Journal of Health Policy and Management, 2020, $x(x), 1-11$ 
Table 7. Examples of SDG 6 Indicators Relevant to Access to Safe Water and Nutrition

\begin{tabular}{|c|c|}
\hline SDGs & 6 \\
\hline $\begin{array}{l}\text { Social determinants } \\
\text { of health }\end{array}$ & Access to safe water \\
\hline \multirow{6}{*}{$\begin{array}{l}\text { SDG } \\
\text { Indicators }\end{array}$} & 6.1.1 Use of safely managed drinking water services \\
\hline & 6.2.1 Use of safely managed sanitation services \\
\hline & 6.3.1 Safely treated wastewater \\
\hline & 6.3.2 Water bodies with good ambient water quality \\
\hline & 6.4.1 Efficiency in water usage \\
\hline & 6.4.2 Availability of fresh-water resources \\
\hline
\end{tabular}

Abbreviation: SDG, Sustainable Development Goal.

distribute responsibilities and efficiently allocate resources for SDG implementation, HiAP as well as the SDGs will struggle to be realized. It will be imperative for Kenya to specifically state how inter-ministerial conflicts can be addressed. ${ }^{71}$ In this study we were able to give an example of how ministries could collaborate or take up leadership roles in facilitating ISC.

Kenya also has both governmental and civil society bodies working on the SDGs, especially at national level. However, the implementation is at local level. Thus, the principle of subnational and local involvement is vital as there is an emphasis on these two levels working together in the 2030 agenda. Local governments have proven to be strategically positioned to harness partnerships between stakeholders and better gauge health priorities at community level. ${ }^{72}$ In Kenya, the HPACs could also align more clearly with the County level SDG structures and groups already present. Their role could be expanded to support oversight mechanisms. This will demonstrate how county-specific decisions and health resources can translate into positive health outcomes. ${ }^{73}$ HPACs could also collaborate more with both the national and local academic institutions and perhaps aim towards a knowledge translation platform role such as the Health Policy (not promotion) Advisory group in Nigeria. ${ }^{74}$ As SDGs have funds allocated both at the national and the county level, the HPACs in Kenya would benefit from aligning some specific plans alongside the SDG agenda. The county health directors and the finance departments that are being set up at the county level should also be lobbied to consider HiAP in their budgeting process.

Offer Insights into the Opportunity of Developing a Monitoring and Reporting Framework for Kenya's HiAP Approach Using SDG Indicators

On monitoring and reporting, we found out that SDG Indicators can be used to inform the progress for sectors outlined under HiAP. Many SDG indicators can be conceptualized as health determinants and HiAP is very essential in realizing policy coherence with the SDGs. ${ }^{68}$ We suggest that to demonstrate this coherence, a HiAP and SDG database could be developed under the given sectors that address the economic, social and political components of development. This could also be used as a basis to further streamline the HiAP priorities in a given county, including collaboration with specific stakeholders.
The potential of the HIA to assess the policy effects of HiAP was explored at the $8^{\text {th }}$ International HIA Conference in Ireland in $2007 .^{75}$ This has also been discussed by other multilateral and national agencies. ${ }^{65,76}$ St-Pierre considered HIA as one of the most structured approaches to adopting HiAP given its ability to better inform decision-makers outside of the health sector of the link between health and their given sectors. ${ }^{76}$ The exploration of HIA as a tool for $\mathrm{HiAP}$ and its implications or relation to the SDG indicators is an interesting area of research.

Pros and Cons of Using the OECD framework

To the best of our knowledge, this is probably one of the first and very few studies that has rigorously applied the OECD framework for academic/scientific research. However, the OECD team did use empirical data in their report on this framework..$^{35}$ The OECD policy framework principles were useful to assess empirical data on policy coherence between the SDGs and HiAP. Even though some principles were indeed represented in the data less saliently than others, including them in our findings report still enabled us to highlight interesting insights. In addition, they indicate areas where the OECD framework can be improved. It was also noted that there was no principle directly addressing funding which is an important influencer of policies in LMICs.

\section{Study Limitations}

At the time of this study, both SDGs and HiAP were at very early adoption stages. As such, the data available was not adequate to derive extensive conclusions from. Due to time and financial constraints, interviews were only conducted with stakeholders at national level. Future qualitative studies on synergies between SDGs and HiAP should include local level key informants, documents and funding structures. We also recommended that future studies use the OECD framework as a priori, that is, to inform the development of the interview guide data collection (including the development of interview guides). Upon availability of SDG indicator data, the proposed HiAP and SDG indicator database can be further analyzed, improved and valuable comparisons among countries made.

\section{Conclusion}

Due to its devolved governance structure, Kenya has a unique opportunity to build momentum for HiAP alongside SDGs. This can be achieved byleveraging on the political commitment SDGs have at all government levels. The establishment of HPACs in collaboration with the SDG structures is a plausible step and running such structures through the devolved government could be important for the long-term sustainability of HiAP. HiAP adoption can also benefit from the long-term planning horizons of the SDGs which have been able to address the quick turn-over of political cycles. Funding for HiAP is crucial for its propagation, especially in LMICs and can be considered in the Budgetary allocations in the SDGs implementation. Institutions and stakeholders both from within and outside the government could collaborate to address policy coherence between HiAP and SDGs. Finally, 
to facilitate moving HiAP from rhetoric to action, HiAP can be monitored concurrently with the SDGs using the SDG indicators.

\section{Acknowledgements}

The first author acknowledges Paul and Maria Kremer Stiftung for funding her $\mathrm{PhD}$ work under which this study was undertaken. The authors would like to thank Dr. Catherine M. Jones for sharing her theoretical and conceptual reflections on policy coherence, which helped us identify the guiding framework for this paper.

\section{Ethical issues}

Ethical approval was obtained from the University of Nairobi and Kenya Medical Research Institute (KEMRI) Ethical Committee in Kenya (P472/06/2016) and the University of Heidelberg Ethical Commission (S-330/2016). A research permit clearance was also obtained from Kenya's National Commission for Science, Technology and Innovation (Permit Number NACOSTI/P/17/83941/15349).

\section{Competing interests}

Authors declare that they have no competing interests.

\section{Authors' contributions}

JM, LG, JT, and AJ developed the concept and design of the study. Data was collected by JM, LT, and JT and analyzed by JM, LT, and NS. The manuscript was drafted entirely by JM. All the authors participated in the critical revision of the manuscript for important intellectual content. AJ and JT were this paper's and overall study's supervisors.

\section{Authors' affiliations}

${ }^{1}$ Heidelberg Institute of Global Health, Heidelberg University, Heidelberg, Germany. ${ }^{2}$ Département de Gestion, Évaluation et Politique de Santé, École de Santé Publique, Université de Montréal, Montreal, QC, Canada. ${ }^{3}$ Department of Sociology, McGill University, Montreal, QC, Canada. ${ }^{4}$ Department of Family and Community Health, School of Public Health, University of Health and Allied Health Sciences, Ho, Ghana. ${ }^{5}$ Department of International Health, Johns Hopkins Bloomberg School of Public Health, Baltimore, MD, USA. ${ }^{6}$ Center for Evidence Based Health Care, Department of Global Health, Stellenbosch University, Stellenbosch, South Africa. ${ }^{7}$ Africa Centre for Evidence, University of Johannesburg, Johannesburg, South Africa. ${ }^{8}$ Institute of Political Science, Heidelberg University, Heidelberg, Germany.

\section{References}

1. United Nations. Transforming our World: the 2030 Agenda for Sustainable Development. New York: United Nations; 2015.

2. Tosun J, Leininger J. Governing the interlinkages between the sustainable development goals: approaches to attain policy integration. Glob Chall. 2017;1(9):1700036. doi:10.1002/gch2.201700036

3. Dora C, Haines A, Balbus J, et al. Indicators linking health and sustainability in the post-2015 development agenda. Lancet. 2015; 385(9965):380-391. doi:10.1016/s0140-6736(14)60605-x

4. Government of South Australia, World Health Organization. Progressing the Sustainable Development Goals through Health in All Policies: Case Studies from Around the World. Adelaide: Government of South Australia; 2017.

5. Waage J, Yap C, Bell S, et al. Governing the UN sustainable development goals: interactions, infrastructures, and institutions. Lancet Glob Health. 2015;3(5):e251-252. doi:10.1016/s2214$109 \times(15) 70112-9$

6. World Health Organization (WHO). Implementation of the 2030 Agenda for Sustainable Development. Geneva, Switzerland: WHO; 2019.

7. World Health Organization (WHO). Shanghai Declaration on Promoting Health in the 2030 Agenda for Sustainable Development. Shanghai: WHO; 2016.

8. Carey G, Crammond B, Keast R. Creating change in government to address the social determinants of health: how can efforts be improved? BMC Public Health. 2014;14:1087. doi:10.1186/1471-245814-1087

9. World Health Organization, Government of South Australia. Adelaide
Statement on Health in All Policies: Moving Towards a Shared Governance for Health and Well-Being. Adelaide: World Health Organization, Government of South Australia; 2010.

10. World Health Organization, Government of South Australia. Adelaide Statement II: Implementing the Sustainable Development Agenda through Good Governance for Health and Well-Being: Building on the Experience of Health in All Policies. Geneva, Switzerland: WHO; 2017.

11. World Health Organization (WHO). Thirteenth General Programme of Work, 2019-2023. Geneva: WHO; 2019.

12. Nilsson M. Understanding and Mapping Important Interactions Among SDGs. Vienna: Background paper for Expert meeting in preparation for HLPF 2017; 2016.

13. Morton S, Pencheon D, Squires N. Sustainable Development Goals (SDGs), and their implementation: a national global framework for health, development and equity needs a systems approach at every level. Br Med Bull. 2017;124(1):81-90. doi:10.1093/bmb/ldx031

14. Thematic Group on Health for All. Health in the Framework of Sustainable Development: Technical Report for the Post-2015 Development Agenda. New York: Sustainable Development Solutions Network; 2014.

15. Kickbusch I. Health in all policies. BMJ. 2013;347:f4283. doi:10.1136/ bmj.f4283

16. World Health Organization (WHO). Demonstrating a Health in All Policies Analytic Framework for Learning from Experiences: Based on Literature Reviews from Africa, South-East Asia and the Western Pacific. Geneva, Switzerland: WHO; 2013.

17. Institute of Medicine (IOM). Global Development Goals and Linkages to Health and Sustainability: Workshop Summary. Washington, DC: National Academies Press; 2014.

18. Rajan D, Mathurapote N, Putthasri W, et al. The Triangle that Moves the Mountain: Nine Years of Thailand's National Health Assembly. Geneva, Switzerland: WHO; 2017.

19. World Health Organization (WHO). Finland Curbs Childhood Obesity by Integrating Health in All Policies. WHO; 2015.

20. Howard R, Gunther S. Health in All Policies: An EU Literature Review 2006-2011 and Interview with Key Stakeholders. Equity Action; 2012.

21. Baum F, Delany-Crowe $T$, MacDougall $C$, Lawless A, van Eyk $H$, Williams C. Ideas, actors and institutions: lessons from South Australian Health in All Policies on what encourages other sectors' involvement. BMC Public Health. 2017;17(1):811. doi:10.1186/s12889-017-4821-7

22. Molnar A, Renahy E, O'Campo P, Muntaner C, Freiler A, Shankardass $\mathrm{K}$. Using win-win strategies to implement health in all policies: a crosscase analysis. PLoS One. 2016;11(2):e0147003. doi:10.1371/journal. pone.0147003

23. Lawless AP, Williams C, Hurley C, Wildgoose D, Sawford A, Kickbusch I. Health in All Policies: evaluating the South Australian approach to intersectoral action for health. Can J Public Health. 2012;103(7 Suppl 1):eS15-19. doi:10.1007/bf03404454

24. Tosun J, Lang A. Policy integration: mapping the different concepts. Policy Studies. 2017;38:6:553-570. doi:10.1080/01442872.2017.1339239

25. Ramirez-Rubio O, Mwoka M, Fanjul G, Plasencia A. Health in All Policies: Opportunities in the Sustainable Development Goals Agenda. Sustainable Development Solutions Network; 2018.

26. Cumming TL, Shackleton RT, Förster J, et al. Achieving the national development agenda and the Sustainable Development Goals (SDGs) through investment in ecological infrastructure: a case study of South Africa. Ecosyst Serv. 2017;27(Pt B):253-260. doi:10.1016/j. ecoser.2017.05.005

27. Riazi-Isfahani S, Moradi-Lakeh M, Mafimoradi S, Majdzadeh R. Universal health coverage in Iran: Health-related intersectoral actions. Med J Islam Repub Iran. 2018;32:132. doi:10.14196/mjiri.32.132

28. Saviano M, Sciarelli F, Rinaldi A, Alowanou G. Healthcare and SDGs governance in light of the sustainability helix model: evidence from the African continent. Sustainability. 2019;11(4):1203. doi:10.3390/ su11041203

29. Qiu M, Jessani N, Bennett S. Identifying health policy and systems research priorities for the sustainable development goals: social protection for health. Int J Equity Health. 2018;17(1):155. doi:10.1186/ s12939-018-0868-z

30. Glandon D, Meghani A, Jessani N, Qiu M, Bennett S. Identifying health policy and systems research priorities on multisectoral collaboration for health in low-income and middle-income countries. BMJ Glob Health. 
2018;3(Suppl 4):e000970. doi:10.1136/bmjgh-2018-000970

31. Scott K, Jessani N, Qiu M, Bennett S. Developing more participatory and accountable institutions for health: identifying health system research priorities for the Sustainable Development Goal-era. Health Policy Plan. 2018;33(9):975-987. doi:10.1093/heapol/czy079

32. Ministry of Health of Kenya. Kenya Health Policy 2014 to 2030. Nairobi, Kenya: Ministry of Health; 2014.

33. Mauti J, Gautier L, De Neve JW, Beiersmann C, Tosun J, Jahn A. Kenya's Health in All Policies strategy: a policy analysis using Kingdon's multiple streams. Health Res Policy Syst. 2019;17(1):15. doi:10.1186/s12961-019-0416-3

34. World Health Organization, Government of South Australia. Implementing the Sustainable Development Agenda Through Good Governance for Health and Wellbeing: Building on the Experience of Health in All Policies. World Health Organization; 2017.

35. OECD. Policy Coherence for Sustainable Development 2018: Towards Sustainable and Resilient Societies. Paris, France: OECD Publishing; 2018.

36. Zainal Z. Case study as a research method. Jurnal Kemanusiaan. 2007;5(1):1-6.

37. Stake RE. The Art of Case Study Research. Thousand Oaks, CA: SAGE Publications; 1995.

38. World Bank Group. Kenya Economic Update: Policy Options to Advance the Big 4. Unleashing Kenya's Private Sector to Drive Inclusive Growth and Accelerate Poverty Reduction. Washington, DC: World Bank Group; 2018.

39. Kenya National Bureau of Statistics. Kenya Demographic and Health Survey. Nairobi, Kenya: ICF Macro; 2014.

40. D'Arcy M, Cornell A. Devolution and corruption in Kenya: everyone's turn to eat? Afr Aff. 2016;115(459):246-273. doi:10.1093/afraf/adw002

41. Friedrich-Ebert-Stiftung (FES). Devolution System Made Simple: $A$ Popular Version of County Governance System. Nairobi, Kenya: FES; 2012.

42. McCollum R, Limato R, Otiso L, Theobald S, Taegtmeyer M. Health system governance following devolution: comparing experiences of decentralisation in Kenya and Indonesia. BMJ Glob Health. 2018; 3(5):e000939. doi:10.1136/bmjgh-2018-000939

43. Bossert TJ, Beauvais JC. Decentralization of health systems in Ghana, Zambia, Uganda and the Philippines: a comparative analysis of decision space. Health Policy Plan. 2002;17(1):14-31. doi:10.1093/ heapol/17.1.14

44. Government of Kenya. Constitution of Kenya, 2010. http://www. kenyalaw.org/lex/actview.xql?actid=Const2010. Accessed February 19, 2019. Published 2010.

45. Ntara C. Devolution and expected impact in Kenya. International Journal of Professional Practice. 2013;4(1-2):7-14

46. International Institute for Legislative Affairs. Understanding the Devolution Architecture. https://ilakenya.org/understanding-the-devolution-architecture/. Accessed December 8, 2019. Published 2019.

47. Hope KR. Devolved government and local governance in Kenya. Afr Asian Stud. 2014;13(3):338-358. doi:10.1163/15692108-12341302

48. United Nations. United Nations Global SDG Indicators Database. https://unstats.un.org/sdgs/indicators/database/. Accessed June 24, 2019. Published 2019.

49. Ministry of Devolution and Planning. Implementation of the Agenda 2030 for Sustainable Development in Kenya. Nairobi, Kenya: Ministry of Devolution and Planning; 2017

50. Ministry of Devolution and Planning. Guidelines for Preparation of County Integrated Development Plans (Revised), 2017. Nairobi, Kenya: Ministry of Devolution and Planning; 2017.

51. SDGs Kenya Forum. Vision 2030's Medium Term Plan as a Framework for Implementation of the Sustainable Development Goals. Nairobi, Kenya: World Wide Fund for Nature (WWF); 2016.

52. SDGs Kenya Forum. Voluntary National Review (VNR) of Progress on the Sustainable Development Goals in Kenya. 2017.

53. UNDESA, RIO+20 UNCSD, UNDP. Sustainable Development in Kenya: Stocktaking in the run up to Rio+20. Nairobi, Kenya: UNDESA, UNCSD, UNDP; 2012.

54. Government of Kenya. Kenya Vision 2030: The Popular Version. Kenya: Government of Kenya; 2007.

55. Government of Kenya. Third Medium Term Plan 2018-2022.
Transforming Lives: Advancing Socio-Economic Development Through the "Big Four." Nairobi, Kenya: Government of the Republic of Kenya; 2018.

56. Ministry of Health of Kenya. Addressing the Social Determinants of Health in Kenya: Framework for Healthin All Policies and Inter-Sectoral Action. Nairobi, Kenya: Ministry of Health; 2013.

57. Mwabu G. Reforming Health Care in Kenya: Prospects for Health-inAll-Policies Approach. Nairobi, Kenya: School of Economics University of Nairobi; 2011.

58. Wangombe J, Muriithi M, Ayagah I. Review of Social Determinants of Health and Health Indicators in Kenya. Nairobi, Kenya: University of Nairobi; 2013.

59. Council of Governors. County Integrated Development Plans 20182022. https://www.cog.go.ke/cog-reports/category/106-countyintegrated-development-plans-2018-2022. Accessed April 15, 2020. Published 2020

60. Gale NK, Heath G, Cameron E, Rashid S, Redwood S. Using the framework method for the analysis of qualitative data in multidisciplinary health research. BMC Med Res Methodol. 2013;13:117. doi:10.1186/1471-2288-13-117

61. Silverman D. Doing Qualitative Research: A Practical Handbook. London: SAGE Publications; 2013.

62. Kenya Vision 2030. http://vision2030.go.ke/. Accessed June 20, 2019.

63. County Government of Vihiga. Second County Intergrated Development Plan 2018-2022. Nairobi, Kenya: Kenya Literature Bureau; 2018.

64. Gulis G. Health impact assessment and the sustainable development goals. Health Promot Int. 2019;34(3):373-375. doi:10.1093/heapro/ daz052

65. Gottlieb L, Braverman PK, Egerte S. Health Impact Assessment: A Tool for Promoting Health in All Policies. Washington, DC: Robert Wood Johnson Foundation; 2011.

66. Holt DH, Rod MH, Waldorff SB, Tjørnhøj-Thomsen T. Elusive implementation: an ethnographic study of intersectoral policymaking for health. BMC Health Serv Res. 2018;18(1):54. doi:10.1186/s12913018-2864-9

67. de Leeuw E. Intersectoral action, policy and governance in European Healthy Cities. Policy Pract. 2015;1(2):111-204.

68. World Health Organization (WHO). Key Learning on Health in All Policies Implementation from Around the World: Information Brochure. Geneva, Switzerland: WHO; 2018.

69. Carey G, Harris P. Developing management practices to support joined-up governance. Aust J Public Adm. 2016;75(1):112-118. doi:10.1111/1467-8500.12169

70. Carey G, Crammond B. What works in joined-up government? an evidence synthesis. Int J Public Adm. 2015;38(13-14):1020-1029. doi: 10.1080/01900692.2014.982292

71. Wong R, van der Heijden J. Avoidance of conflicts and trade-offs: a challenge for the policy integration of the United Nations Sustainable Development Goals. Sustain Dev. 2019;27(5):838-845. doi:10.1002/ sd.1944

72. Bustreo F, Mshinda H, Hinton R, Hausmann-Muela S, Tanner M. Commentary: primary health care in Tanzania - leading the way through innovation. EClinicalMedicine. 2019;13:12-13. doi:10.1016/j. eclinm.2019.07.010

73. Afnan-Holmes $\mathrm{H}$, Magoma M, John $\mathrm{T}$, et al. Tanzania's countdown to 2015: an analysis of two decades of progress and gaps for reproductive, maternal, newborn, and child health, to inform priorities for post-2015. Lancet Glob Health. 2015;3(7):e396-409. doi:10.1016/ s2214-109x(15)00059-5

74. Uneke CJ, Ndukwe CD, Ezeoha AA, Uro-Chukwu HC, Ezeonu CT. Implementation of a health policy advisory committee as a knowledge translation platform: the Nigeria experience. Int $\mathrm{J}$ Health Policy Manag. 2015;4(3):161-168. doi:10.15171/ijhpm.2015.21

75. Metcalfe $\mathrm{O}$, Higgins $\mathrm{C}$. Healthy public policy--is health impact assessment the cornerstone? Public Health. 2009;123(4):296-301. doi:10.1016/j.puhe.2008.12.025

76. St-Pierre L. Governance Tools and Framework for Health in All Policies. National Collaborating Centre for Healthy Public Policy, International Union for Health Promotion and Education, European Observatory on Health Systems and Policies; 200. 